\title{
Using Information Technology In Teaching Of Business Statistics In Nigeria Business School
}

Dallah Hamadu, University of Lagos, Nigeria

Ismaila Adeleke, University of Lagos, Nigeria Ike Ehie, Kansas State University, USA

\begin{abstract}
This paper discusses the use of Microsoft Excel software in the teaching of statistics in the Faculty of Business Administration at the University of Lagos, Nigeria. Problems associated with existing traditional methods are identified and a novel pedagogy using Excel is proposed. The advantages of using this software over other specialized statistical packages (SPSS, Minitab or Stata) are simplicity, universality, accessibility, increased acquisition of skills, and, more importantly, reduced cost for students and instructors alike particularly for those in developing economies. Several examples are introduced to illustrate the use of Excel in teaching statistics in a business school. Moreover, this proposition is partially motivated by an intervention program funded by the USAID that resulted in the acquisition of information and communication technology (ICT) laboratories.
\end{abstract}

Keywords: Business Statistics; Information Technology; Microsoft Excel; Developing Economy; Learning Goals

\section{INTRODUCTION}

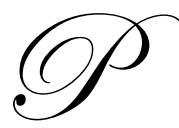

otentially, there are different ways of teaching statistics to business students than any other subject in the business school curriculum. The observed variations in pedagogy and content reflect differences among schools and lecturers, but also reflect a change to information technology (Bell, 2000). For about six years, we have been involved with teaching the course 'Business Statistics I\&If' at the University of Lagos. The course is compulsory to all majors in the Faculty (Accounting, Actuarial Science, Insurance, Finance, Management, Marketing, and Industrial Relation and Personnel Management). Through our interactive feedback from students taking this course, we have received several commendations and complaints from the students. Most of them recognize that the subject is very important and useful for their future careers, but that it is somewhat difficult to learn given the numerous formulae needed in solving business problems. The role of information technology in teaching statistics has been widely discussed. A large number of contributions have been offered on the potential and effectiveness of Excel in teaching business statistics (for more insights, see Bell 2000; Brandwein and Rosenberg, 1994; Mill 2002; Cicchitelli, 2006; and Sungur, 2008). Compared to the rate of changes in computer technology in recent times, the rate of changes in the instructional methods is slow, especially in developing economies such as Nigeria. One area where this notion is very apparent is in the use of technology to teach statistics in Nigerian business schools, in general, and University of Lagos, in particular.

Our schools rely solely on federal government subvention to fund the development of information technology needed; however, this subvention is grossly inadequate (ASUU, 2009). As a result, there are shortages of computers in our educational system as compared to well funded educational systems in the developed economy. Nevertheless, there have been a number of positive developments in the last three years. Recently, the Faculty of Business Administration at the University of Lagos has acquired two computers laboratories, each with a capacity of 100, through the University of Lagos USAID and Kansas State University partnership project. Hence, we are now in a better situation to propose a modern students' learning pedagogy with the applications of Microsoft Excel in business statistics in line with the new faculty's mission and learning goals. 


\section{EXISTING METHODS}

Business Statistics is compulsory to all students in the Faculty of Business Administration at the University of Lagos. As a graduating requirement for an award of Bachelor of Science in the faculty, all majors in Accounting, Actuarial Science, Insurance, Finance, Management, Marketing, and Industrial Relation and Personnel Management are required to pass the course. In addition, students from Education Administration are required to take and pass the course before graduation. The six units' course is divided into two semesters (the second semester, 200 level, and the first semester, 300 level). The method used in teaching is mainly teacher-centered and lecture-based. Lecturers deliver lectures in a passive mode while students watch, listen and take notes. If students require help, they can attend tutorial classes. This method often encounters problems because of the large number of students who need to be served. In each lecture, the instructor teaches and solves example problems from beginning to end of the class period. There is no enough time for students to ask questions in class or discuss the material with their fellow classmates. Learning is based heavily on lecture notes and textbooks with no computer laboratory work, teamwork, or group discussions. Retention of the style of teaching is very minimal; hence, we propose the use of information technology in teaching the business statistics course.

\section{RECENT DEVELOPMENTS}

Over the years, the faculty, in its bid to reposition itself to be at the forefront of business schools producing high quality business graduates for the Nigerian and global economy, has embarked on reforms on a series of programmatic and curriculum development projects that include capacity building in collaboration with development partners. The most important among these is the partnership between the University of Lagos, faculty of Business Administration, USAID, and Kansas State University. The goal of the UNILAG-USAID-KSU Project is to strengthen the Faculty of Business Administration to begin a process of short and long-term changes that will move it from where it is currently to a new level of functioning that is informed by world-class standards and employers' expectations; that is, the pursuit of excellence in modern management education where the skills taught by the faculty are the skills needed to drive the Nigerian economy for development. The core objectives of this project are to: 1) engage the senior leadership team in sustainable change management for continuous program improvement, 2) assess, redesign and implement a revised faculty curriculum consistent with international standards and the needs of the private sector, 3) introduce updated teaching pedagogy, including the use of technology in instruction to increase teaching effectiveness, 4) provide opportunities for faculty development and collaborative applied research, 5) engage the private sector in the faculty programs, and 6) better prepare students for and link them with career opportunities (see FBA Strategic Plan, 2009). In addition, the faculty now has two fully operational modern computer laboratories equipped with WINDOWS XP, Microsoft Office and Internet facilities. The two laboratories have the capability of about 200 students. This is quite adequate since none of the sessions have a capacity of more than 100 students.

\section{PROPOSED METHODS}

To address the current problems, we need to emphasize on student learning consistent with the new vision and mission of the faculty. Problem-based learning examples and case studies are important strategies we are going to adopt. The use of Microsoft Excel in teaching statistics in business may be an important and appropriate method in producing students that can solve business problems using statistics as opposed to producing business graduates who understand only statistical theory.

\section{Pedagogy}

The first step in designing a statistics course is to look at programme objectives. Learning goals are the product of the Faculty of Business Administration's reflection on the skills, attitudes, and knowledge that they expect students to acquire during studentship period leading to their graduation. In this regard, business graduates should possess: 1) critical and analytical reasoning and problem-solving skills, 2) effective communication skills, 3) basic information technology skills, 4) good knowledge of theory and application of functional areas of business, and 5) an understanding of organizational decisions in legal and ethical matters. 
Looking at these programme objectives, the statistics instructor can contribute to these goals in many ways. For example, among others: 1) cases where the use of data supported by statistical analysis leads to improved decision-making can develop a student's ability in critical thinking and problem-solving skills, 2) examples that provide practice in Excel and exposure to various functions and features of Microsoft Excel that are new to students contribute to developing more general problem analysis skills and improved information technology skills, etc.

The next step is to look at the course objectives. In our opinion, we would like students taking this course to have added value with: 1) an understanding of nature and the importance of statistics in business studies, 2) the ability to use basic statistics to summarize data, including descriptive statistics, frequencies, charts and graphs, 3) an understanding of variation and to perform further analysis (Hypothesis testing, Correlation, Regression analysis, Modeling, and Forecasting.), 4) ability to compute Index Numbers and Ratios using Microsoft Excel functions, and 5) an understanding on how to interpret case study analysis results to make appropriate managerial decisions.

\section{Basic Teaching Algorithms}

Statistical analysis of business data involves working with large data and computer software is frequently required to conduct analyses. The data to be analyzed are entered into an Excel spreadsheet. We use Excel as a medium of teaching statistical procedures for analyzing and presenting data since in our environment it is available and widely used in business organizations, and it is expected that knowledge gained in the business school can be put to use soon after the graduate is employed.

Examples of data used throughout this article are official data published by the Central Bank of Nigeria (CBN, 2007). The choice of these real life examples acquaint students with official government data that are used for business and economic transaction records and decisions.

The following steps describe how to use the Excel chart wizard to construct a pie chart for budget estimates for selected government ministries using CBN data exhibited in cells E1:F5

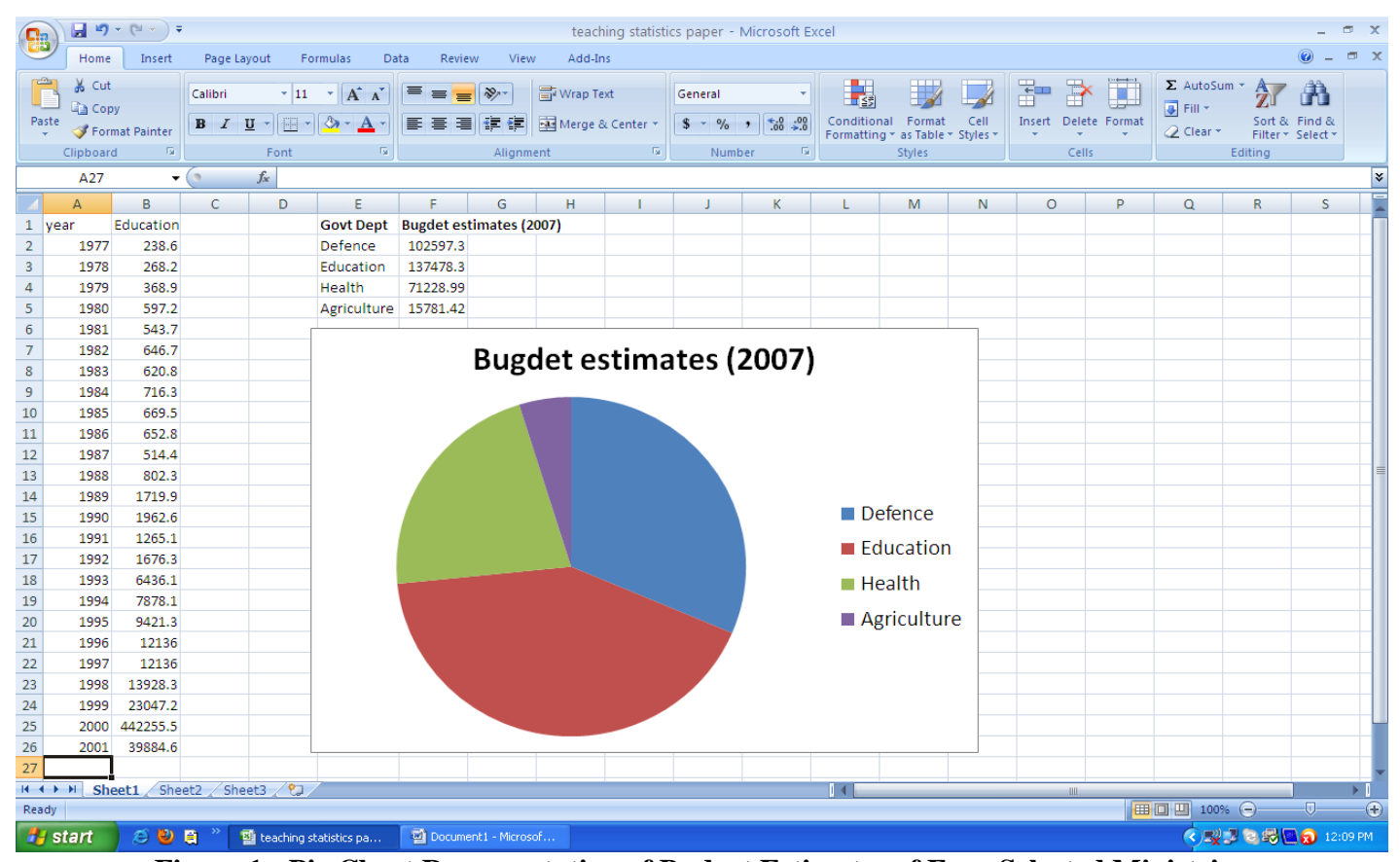

Figure 1: Pie Chart Representation of Budget Estimates of Four Selected Ministries

Source: Central Bank of Nigeria 
Step 1: Select cells E1:F5.

Step 2: Select the insert pull-down menu and choose the chart option (or select the chart wizard button on the standard toolbar).

Step 3: Select "pie’' in the chart-type list dialog box.

The following steps describe how to use Excel chart wizard to construct a line graph for budget estimates for Education Ministry from the CBN data for the years 1977-2001 given in cells A1:B26:

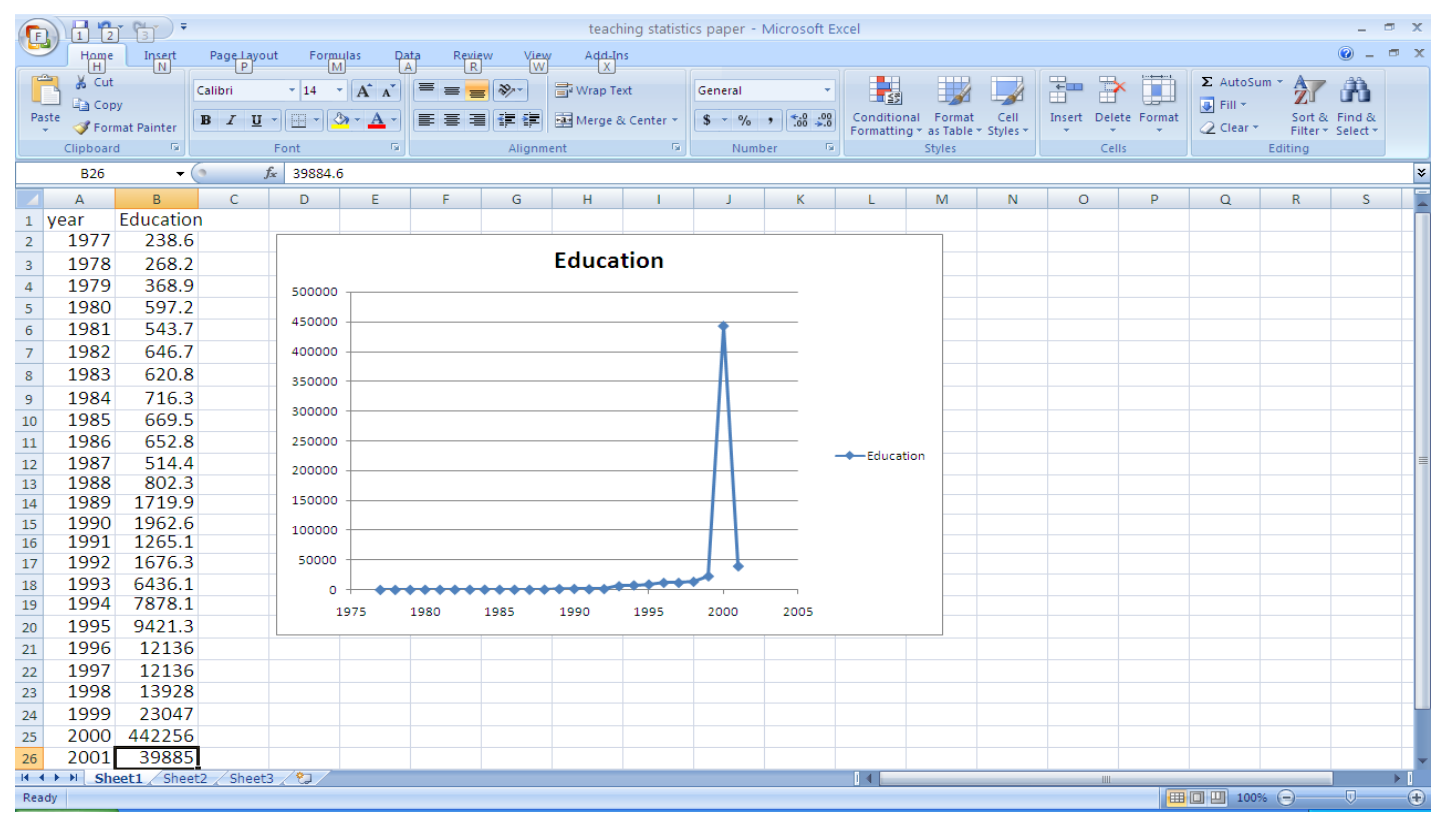

Figure 2: Line Graph for Budget Estimates of Education Ministry from 1977 to 2001

Source: Central Bank of Nigeria

Step 1: Select cells A1:B26.

Step 2: Select the insert pull-down menu and choose the chart option (or select the chart wizard button on the standard toolbar.

Step 3: Choose "scatter" in the chart-type list when the chart-type (chart wizard) dialog box appears.

Step 4: Choose"scatter with smooth line and markers".

To perform descriptive statistics with Microsoft Excel spreadsheets, the following steps can be used:

Step 1: Select the Tools pull-down menu.

Step 2: Choose “Data Analysis' option.

Step 3: Choose “Descriptive Statistics'from a list of analysis tools.

Step 4: When the dialog box appears,

Enter'B1:D10' in the input range box

Select 'Label' in first row

Select 'Output' range

Enter"A12' in the output range box

Select"Summary Statistics"

Select' 'OK' 


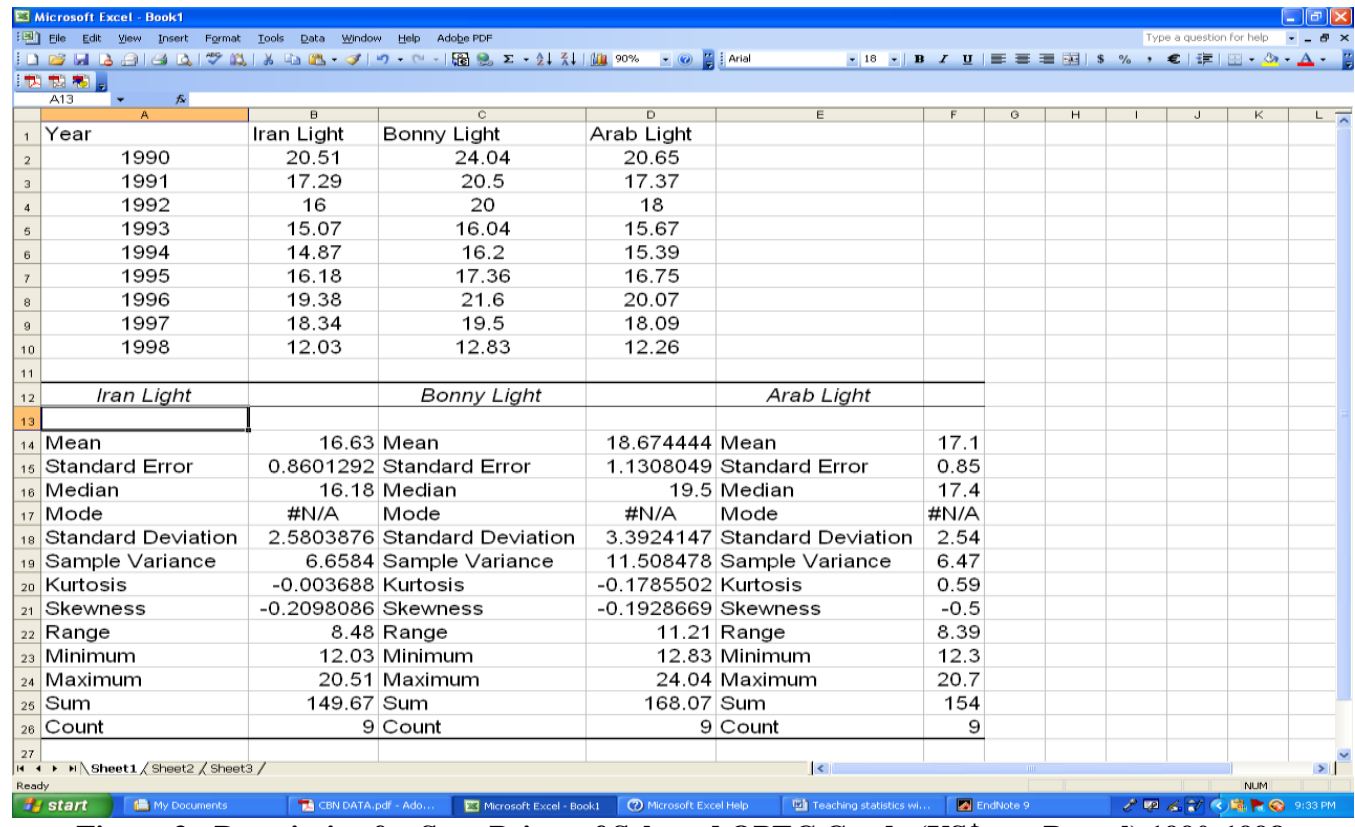

Figure 3: Descriptive for Spot Prices of Selected OPEC Crude (US\$ per Barrel) 1990-1998

Source: Central Bank of Nigeria applied:

To perform correlation analysis with Microsoft Excel spreadsheets, the following basic steps can be

Step 1: Select the Tools pull-down menu

Step 2: Choose "Data Analysis' option

Step 3: Choose “Correlation' from a list of analysis tools

Step 4: When the dialog box appears,

Enter"A1:C10' in the input range box

Select'Output' range

Enter"A12' in the output range box

Select' 'OK'

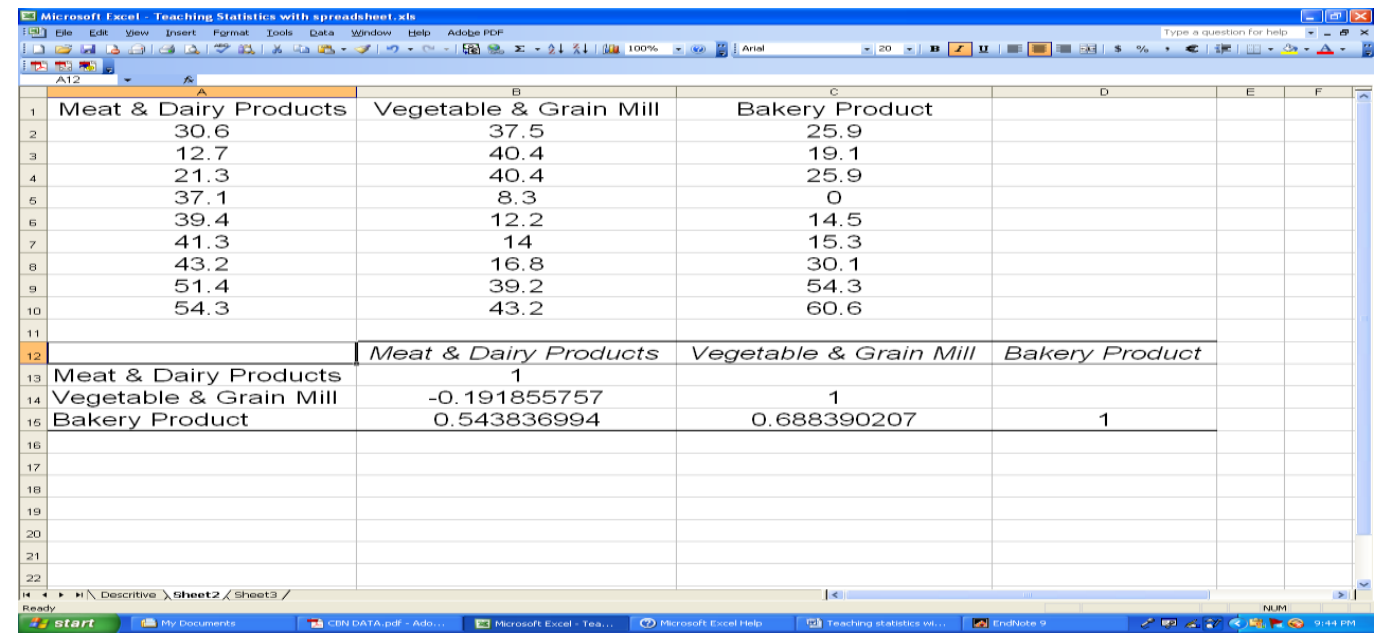

Figure 4: Correlation of Nigeria's Average Manufacturing Capacity Utilization Rates between Selected Sub-sectors (1994-2002)

Source: Central Bank of Nigeria 
To perform the Analysis of Variance with Microsoft Excel spreadsheets, do the following:

Step 1: Select the Tools pull-down menu

Step 2: Choose 'Data Analysis'option

Step 3: Choose "Anova: Single Factor" from a list of analysis tools Select' 'OK"

Step 4: When Anova: Single Factor dialog box appears,

Enter"A1:C10' in the input range box

Select“'Columns"

Select 'Labels' in first row

Select' Output' range

Enter"A12'in the output range box

Select'OK"

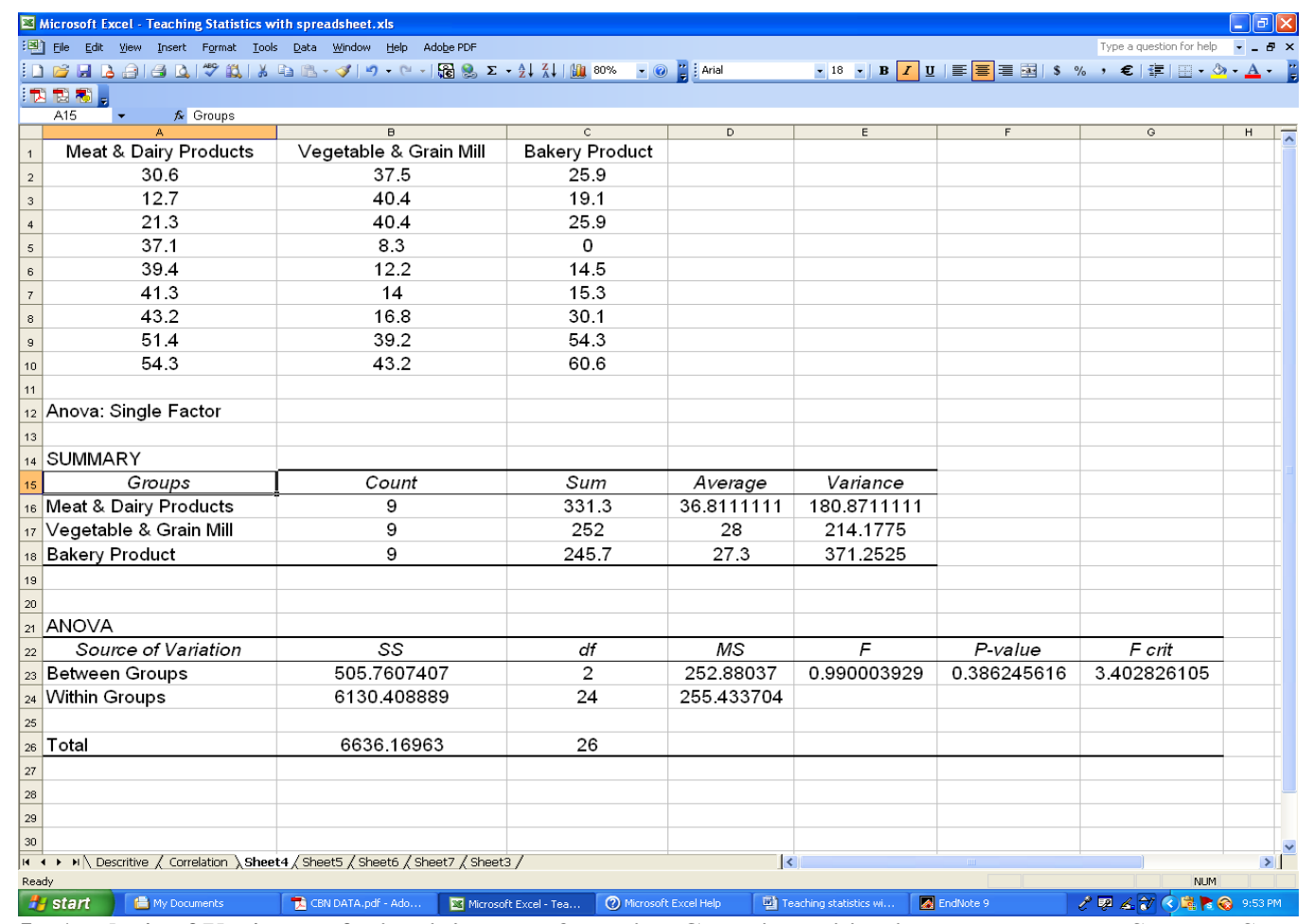

Figure 5: Analysis of Variance of Nigeria's Manufacturing Capacity Utilization Rates between Selected Sub-sectors (1994-2002)

Source: Central Bank of Nigeria

To perform Regression Analysis with Microsoft Excel spreadsheets, apply the following:

Step 1: Select the Tools pull-down menu

Step 2: Choose 'Data Analysis'option

Step 3: Choose "Regression' from a list of analysis tool

Step 4: When the dialog box appears,

Enter"A1:A10' in the input $\mathrm{Y}$ range box Enter"B1:B10' in the input $\mathrm{X}$ range box Enter"A12' in the output range box Select 'OK' 


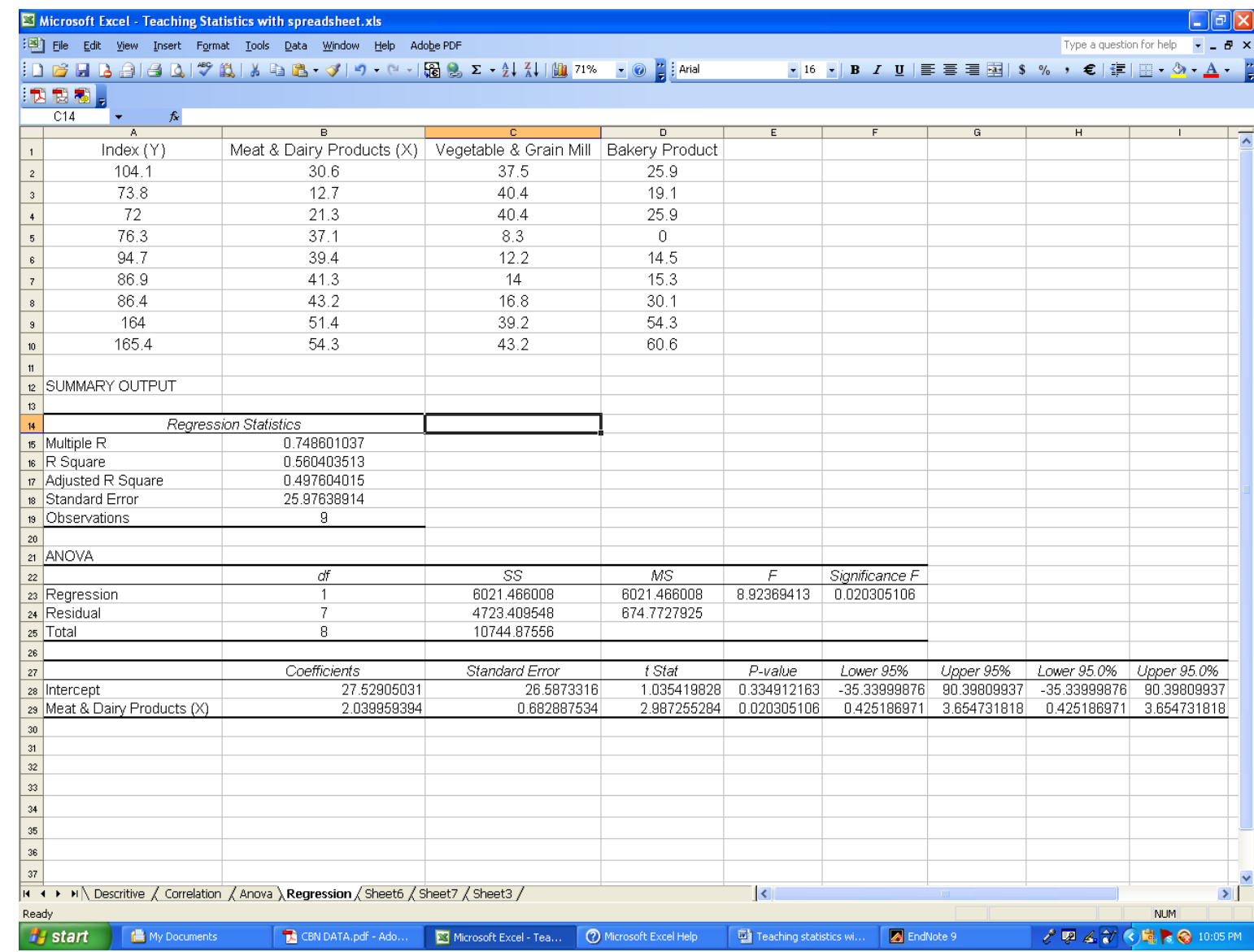

Figure 6: Regression Analysis of Nigeria's Average Manufacturing Capacity Utilization Rates of Selected Sub-sectors and Index of Energy Consumption (1994-2002)

Source: Central Bank of Nigeria

\section{CONCLUSION}

Our proposal to teach statistics to business students using Microsoft Excel spreadsheets is suitable and creates an interactive learning environment. The spreadsheets can be used along with real life business cases for laboratory class demonstrations and for individual or group assignments. Contrary to the traditional teaching methods, the use of Microsoft Excel spreadsheets will facilitate understanding of business statistics and business issues through the use of real, practical and business-oriented cases. More importantly, the constraints of the instructor being limited to few simulated observations are overcome using large real life data with Excel, which, allows students to emphasize more on interpretations of analysis results rather than calculations. Finally, it is expected that the new pedagogy will move the business school from where it currently is to a world-class standard where employers' expectations are met; that is, the pursuit of excellence in modern management education where the skills taught by the faculty are the skills needed to drive the Nigerian economy for development.

\section{AUTHOR INFORMATION}

Dallah Hamadu is a senior lecturer in the Department of Actuarial Science and Insurance, Faculty of Business Administration, University of Lagos. He served as Sub-Dean of the Faculty of Business Administration from 2009 to 2011. He received his BSc (First Class Honours) Math/Statistics from University of Maiduguri and a PhD Statistics from University of Lagos. His areas of teaching include Business Statistics, Business Mathematics, Research Methods, Stochastic and Simulation Modeling, Survival and Loss Models and quantitative Analysis. His 
research areas include; Bootstrap Methods, Business Statistics, Stochastic Modeling and Forecasting, Loss modeling, and Statistical Capacity Building. He has published in several reputable academic journals. E-mail: dhamadou@unilag.edu.ng

Ismaila Adedeji is of the Department of Actuarial Science and Insurance, University of Lagos. He has a Ph.D degree in Statistics and his research areas include; Business Statistics, Actuarial Statistics and Risk Modeling. E-mail: iadeleke@unilag.edu.ng

Ike C. Ehie is a professor of Operations and Supply Chain Management in the College of Business Administration t Kansas State University, Manhattan, Kansas. He served as the Associate Dean of the College of Business from 2002 to 2008. Prior to this, he was department head and professor of Management at Southeast Missouri State University, Cape Girardeau, Missouri. He received his Ph.D. from the University of Missouri-Rolla (now Missouri University of Science \& Technology) in Engineering Management. His areas of teaching include Operations Management, Supply Chain Management and Quantitative Management. His research interests include RFID adoption/implementation, supply chain design, global manufacturing strategies, and performance evaluation. He has published in academic journals such as Interfaces, Omega, European Journal of Operations Research, Production \& Inventory Management Journal, International Journal of Production \& Operations Management, Computers in Industry, Journal of Manufacturing \& Technology Management, and International Journal of Production Economics. He recently served as the co-PI of a USAID grant to strengthen the business curriculum at the University of Lagos, Nigeria. E-mail: iehie@ksu.edu

\section{REFERENCES}

1. Academic Staff Union of Nigeria Universities (2009), Bulletin of the Nigerian Academic Staff Union (ASUU) on the State of Nigeria Universities.

2. Bell, P. C. (2000), Teaching Business Statistics with Microsoft Excel, Informs Transactions on Education, Vol. 1 No.1.

3. Brandwein, A. C. and Rosenberg, L. (1990) Teaching the Introductory Statistics Course with a Lotus 1-2-3 Package, ICOTS-3, pp. 183-187.

4. Central Bank of Nigeria (2007), Bulletin of the Central Bank of Nigeria (CBN), Garki, Abuja.

5. Cicchitelli, G.(2006), Demonstrations in Probability and Statistics Using Excel, ICOTS-7, pp. 1-4.

6. Faculty of Business Administration (2009), Strategic Plan for the Faculty of Business Administration (FBA), University of Lagos, Akoka.

7. Mills, J. D.( 2002), Using Computer Simulation Methods to teach Statistics: A review of the literature. Journal of Statistics Education, 10(1).

8. Sungur, E. A. (2008), Some Content Options in Online Statistics Courses, Statistical Education Section, JSM Proceedings , Denver, USA, pp. 335-337 